\title{
SIMULATION PROJECT MANAGEMENT BY MODIFIED GAUSS S-CURVE
}

\author{
VLADIMIR KRIŽAIĆ ${ }^{1}$, TIBOR RODIGER ${ }^{2}$ AND SARAJKO BAKSA ${ }^{3}$ \\ Polytechnic of Međimurje in Čakovec \\ 40000 Čakovec, Bana J. Jelačića 22a \\ 1vvladimir.krizaic@mev.hr \\ 2 tibor.rodiger@mev.hr \\ ${ }^{3}$ sarajko.baksa@mev.hr
}

Key words: Project management, cash flow, S-curve, 3D model - MGSC, FEM mesh.

\begin{abstract}
Contemporary project management rises to the level of various associative groups, going beyond project management (PM) in a specific, defined activity. Processes not directly related to one activity are becoming more important. Planning a process group by cash-flow methods or S-curve defines the given process one-dimensionally, while using modified Gaussian curve enables process simulations with two-dimensional or 3D modeling. Any financial condition of the project is modeled or simulated by two variable function and today's popular iterative numerical mathematical methods suitable for software mathematics, i.e. computer operations, depending on duration and cost or amount of project investment. Therefore, using a new method of Modified Gaussian S-Curve (MGSC) for modeling and simulating creates an $\mathrm{nM}$ model of project execution with the possibility of PM initial optimization and monitoring process group. Future project reliability is measured and regulated by given MGSC inverse curves.
\end{abstract}

\section{INTRODUCTION}

Rapid development of business process management technology (BPM) has also accelerated the establishment of project management (PM). New CAD, BIM, Digital Twins (DT) and SMART technologies and methodologies within Integrated Information Systems (IIS) have contributed to daily monitoring [1] method of companies and project management systems. Project system planning and regulation, i.e. process group planning, supervision and control are essential to these new methods. Although standardization technology does not follow the path of the Third and Fourth Industrial Revolution, programming alongside operational research has made the development of dynamic structural programming (DSP) method [2] possible. This method, combined with operational research as a tool for optimal project management, transforms the static construction organization project (COP) into dynamic COP or dynamic project management (DPM) processes referred to as PM. Introducing a company-wide Enterprise Resource Planning (ERP) system [3] is a key investment requiring huge resources and it can significantly affect an organization's future competitiveness and performance. Therefore, modeling an Application Programming 
Interface (API) [4] creates tools that can help facilitate research related to Building Information Modeling (BIM). Robotics enables technological expansion beyond organizational limits and it is therefore necessary to establish dynamic models of norms using vector planning [5] and improve them by optimizing production processes [6]. Thus, problems are eliminated through model standardization of business processes. A business system strives to optimize its economic and organizational elements. Closing the gap between organizational solutions and technological advances creates a production model with DT and cyber-physical systems (CPS) [7].

The industry is simultaneously searching for new ways of keeping up with rapid data transformation through CPS subset which is already being used in process automation, especially in the digital world. Therefore, numerical mathematical iterative equations [8] contribute to algorithms as an IT tool in defining DT, CPS and model standardization of construction production by DSP method. Simulation tools such as Matlab applications [9] become an informative aid in defining CPS analytically and graphically.

It is difficult to clarify the S-curve because of its inaccurate definition in a 2D system with process and risk occurrence acting as aggravating factors. Specifically, current engineering Scurve observation and definition by linear equations seem to pose a problem. Computer graphics developers specializing in CAD and DT tools use iterative, linear Casteljau, Bezir and Hermite equations to calculate curvature. However, the 2D problem is already being solved by contemporary software, supported by differential equations using Runge-Kutta system in finite element methods and utilizing topographic 3D representations of various spatial shapes and design

Consequently, MGS with two variables and flow curve simulation function closely resentibl
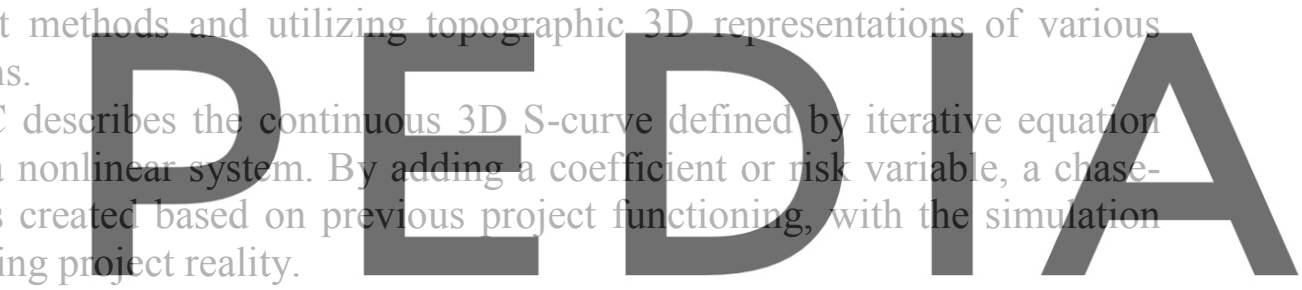

PM simulation with MGSC provides an iterative and more precise way of defining MP

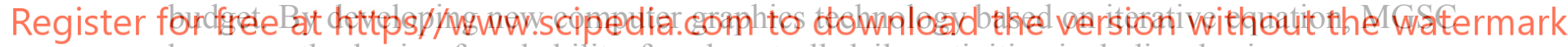
becomes the basis of probability for almost all daily activities including business processes with PM planning inside a business system and connecting to business applications via BIM, DT and AI systems.

State and methods of planning and defining the cash flow curve are described at the beginning of the chapter review, followed by presenting the origin of MGSC with previous research equations. Also, an IT manager can use simulations of initial risk as a variable so the project plan can be defined more accurately.

\section{S-CURVE METHOD FOR ANALYSIS AND PLANNING}

Planning is essential in management and poses a big problem in every business system. Obsolete and outdated norms distance us from reality and an organization cannot keep up with the rapid technological development. This backlog can be cleared by replacing the static management of a construction organization project with the dynamic POG organization [10], a precondition for precision planning and reducing business risk in contemporary planning and monitoring within the PM process groups. Nowadays, SWOT analysis gathers nonquantitative data representing system resource capabilities and deficiencies. The historical 
development of mathematics [11] has enabled computerized process modeling (Fig. 1) complemented by DSP method in construction work.
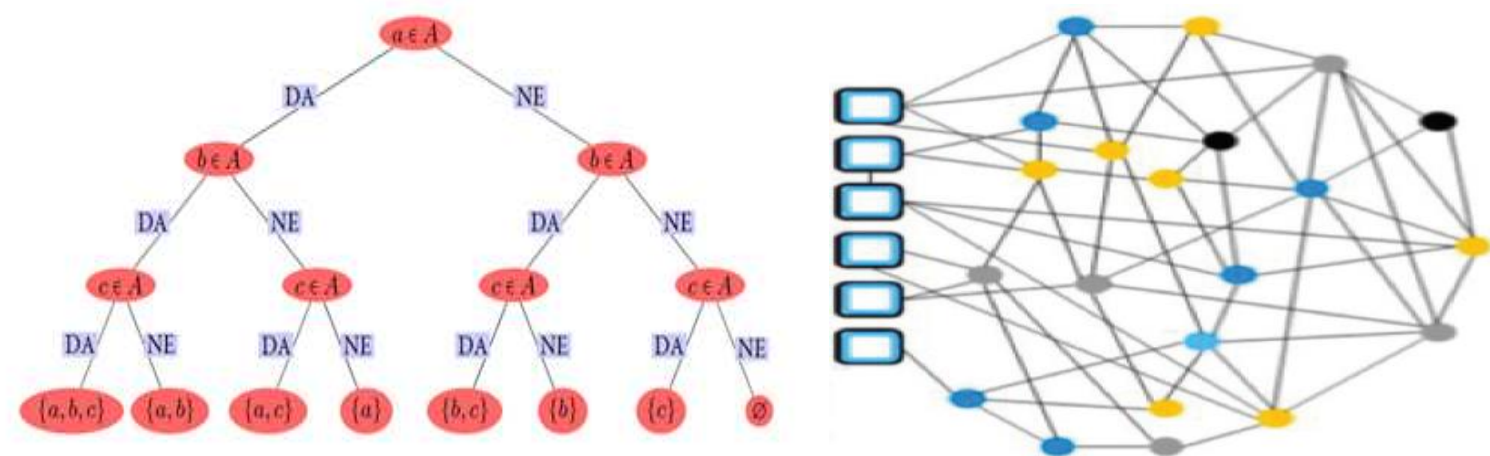

Figure 1: Binomial set (Nakić) and cyber-physical-production-system (Faller, Höftmann)

The method improves operational research and dynamic programming. All the combined factors provide optimal control in terms of achieving process maximum or minimum, calculated by recurrence equation (1).

$$
f n(p)_{j}=G(p)+f n-1(p)_{j, k}
$$

The equation defines the final process stage $f(p)$ in regard to the initial $G(p)$ and the previous $\mathrm{fn}-\mathrm{I}(p)_{\mathrm{j}, \mathrm{k}}$. In this wy, all processe are functionally linked but als suitable fo simple and unified systems. Multi-stage processes are defined by vector states via recurrence equations. Nowadays, along with stochastic var planning processes of the PHRT system, the Value Analysis (EVA) curve. In practice, divergence from plant identified in accordance with project plan and realization. Various mathematical solutions

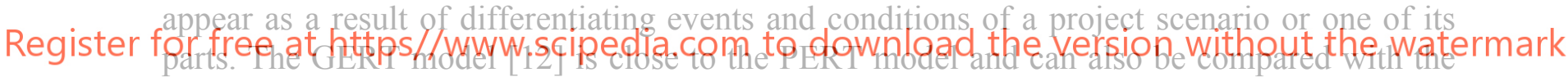
queueing theory model [13]. Attempts at PERT, i.e. simulating an activity's most likely time as weil as the probability of the sum of events in system stage and condition [14], create linear algebraic equations defining the dimensions of risk. However, it is possible to define multiple EVA scenarios for projects (Fig. 2) since a single project scenario does not correlate with other projects.

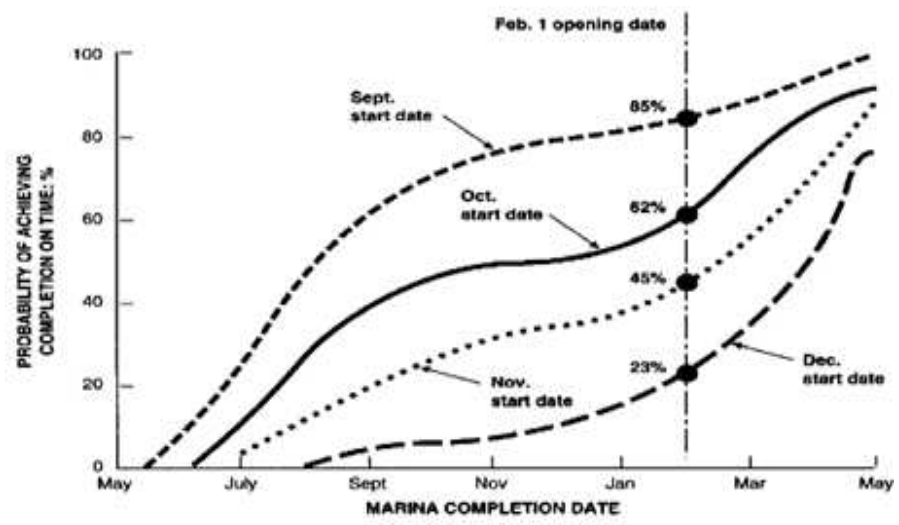

Figure 2: Estimated project duration and cost (Godfrey, Halcrow \& Partners) 
In recent years, probabilistic forecasts of project performance, as well as software use of stochastic S-curves in generating stochastic S-curves and simulations, display dispersion deviation [15] from the S-curve according to Gaussian density function of cost and time distribution (Fig. 3). However, the one-dimensionality of these curves or 2D function representations remains a problem.
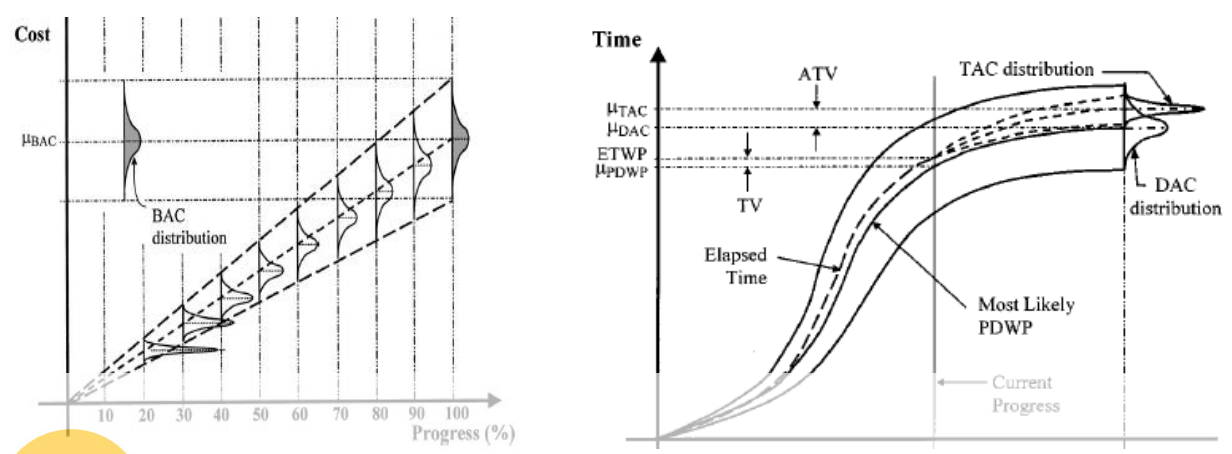

Figure 3: Probabilistic dispersion of project cost and duration (Barraza, Back \& Mata)

New methods of PM risk management provide new variables which make case-flow diagram forecasting more accurate, so various governments started using Risk Analysis and Management Method (CRAMM) developed by the British government and OCTAVE (Operationally Critical Threat, Asset and Vulnerability Evaluation) which provides security

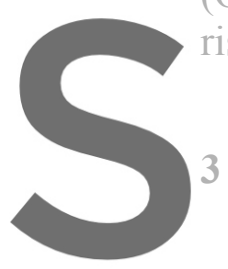
risk assessments and plans. Identifying and qu
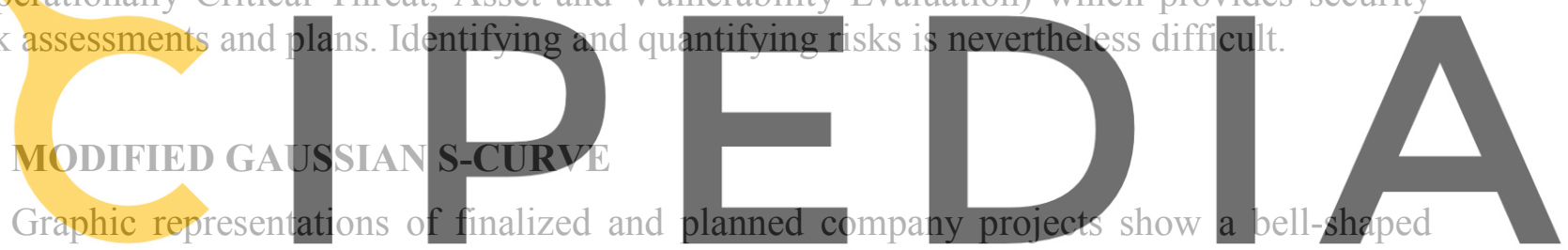

differentiation, more precisely, a deviation of situation curves or cash flow project curves

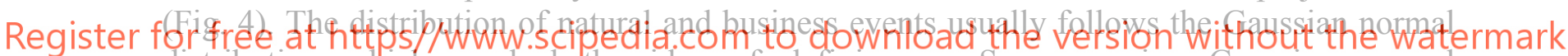
distribution which sparked the idea of defining an S-curve using Gaussian normal distribution. For initial definition of the given curves, the statistical model of defining quadratic linear equations by Gaussian least-squares method $[16,17]$ was applied on finalized and planned projects (Fig. 4) of the given company. The results can be seen in Mathcad software with realization dispersion curve observed as a semicircle above and under the planned straight curve.
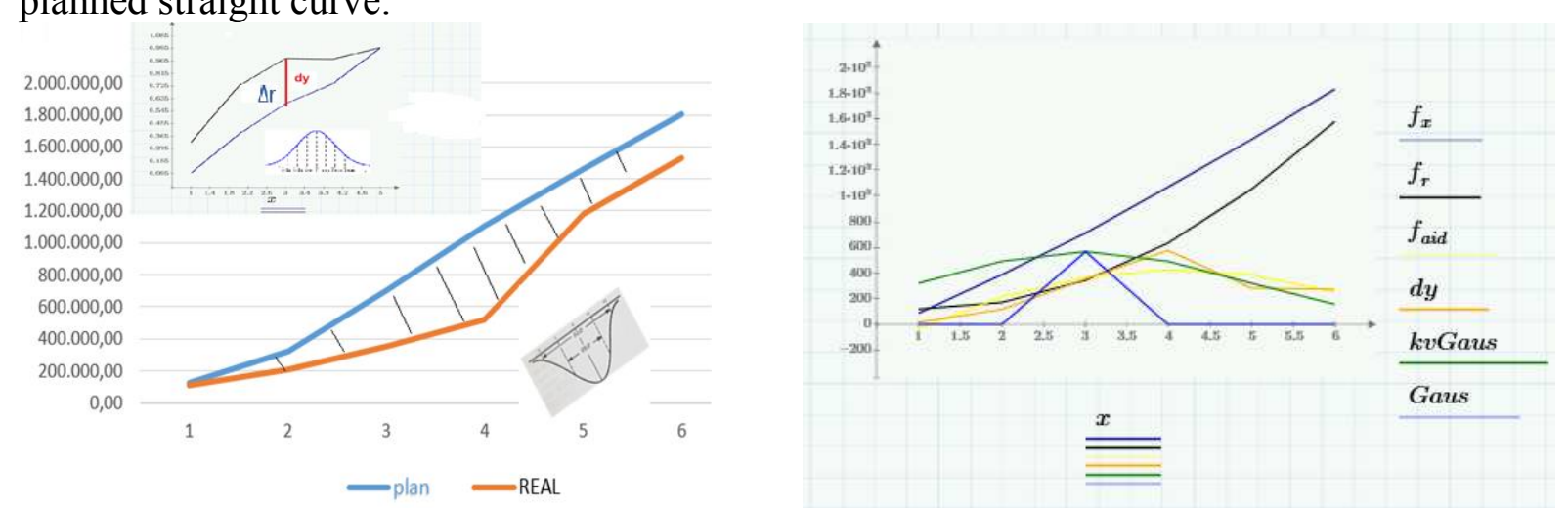

Figure 4: Project data distribution curves of the company Međimurje Graditeljstvo 
The angle of the set domain increases as project number grows, i.e. data is more scattered. Therefore, the equivalent measure enabling data comparison by functions $t$ (time, month) and $T$ (costs or situations month by month) is introduced. The common Gaussian dispersion model displays deviations in project finances which is made possible by comparing distribution of the difference between situations, more precisely, S-curves of planned and finalized projects.

For a given project, planned and finalized discrete functions $y$ i $r$ are written in equation (2) while their difference $d y$ or $f(x)-f(r)$ is a discrete curve and a replacement continuous Gaussian curve in equation (3).

$$
\begin{gathered}
f(x)=a 1+a 2 \cdot x+a 3 \cdot x^{2} \\
k v \text { Gaus }=\frac{1}{\sigma \cdot \sqrt{2 \cdot \pi}} \cdot e^{\frac{-(x-\mu)^{2}}{k v \cdot \sigma}}
\end{gathered}
$$

Based on a number of projects and links of the Gaussian equation's main variables to field data or situations in construction, a new general definition of MGSC [18] was created as function of production time and project cost or project situation equation (4).
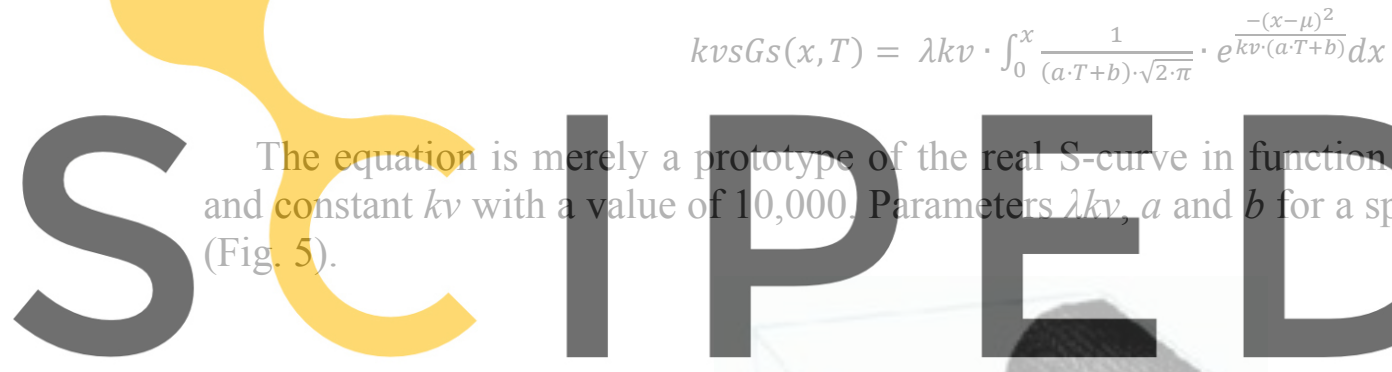

(4)

Register for free at https//www.scipedia.com to download the version without the watermark

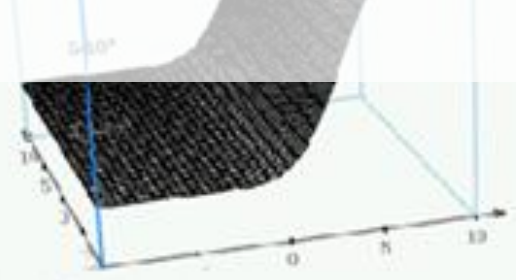

Figure 5: Modified Gaussian S-curve

\section{MGSC SIMULATIONS}

Since EVA or S-diagrams are popular nowadays, adding quantified risk will improve PM and make decision-making more realistic with MGSC. According to the first assumption, risk distribution is based on Gaussian distribution. Previously executed projects prove that project deviation happens mid-project approximately and equals half of the investment at a given point (Fig. 6). Therefore, in the second assumption, $d y$, the difference between planned and 
final S-curve is identified with $\Delta r$, i.e. financial deviation is identical to the equivalent risk magnitude.

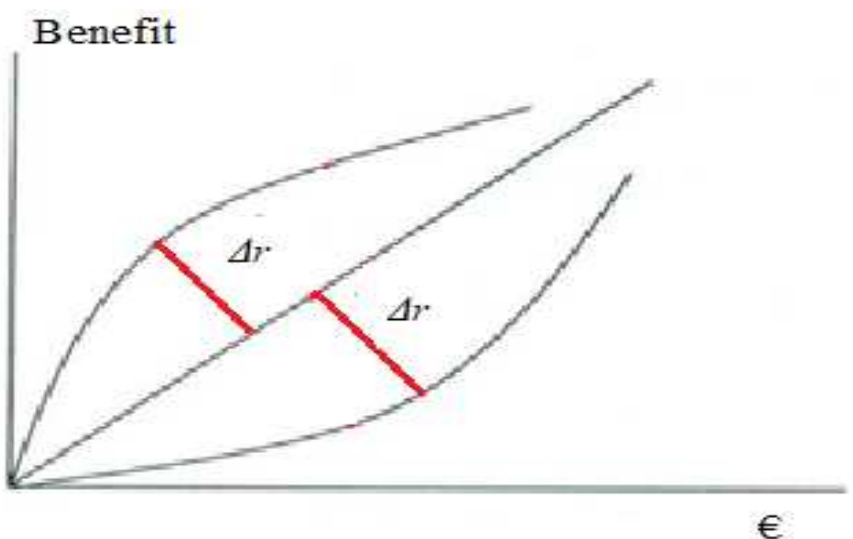

Figure 6: Utility - risk dispersion

Utility function does not only link probability and number of events into a function dependency but can also quantify risk. Methods of Monte Carlo simulations and Beta risk are trying to be quantitative but are still subject to intuition coefficients. TREEPlan as well as Monte Carlo and PERT modeling and simulation are used to collect and analyze risk data by number-rendering based simulations which are a matter of chance, so decision-making may also be accidental. The initial step in construction, bidding, is always marked by uncertainty
and risk. However, a clear tabular overview of possible measure cam be created by intuitively defining or estimating percentages and probabilities, whild taking into account uncertainties in all further activities or ev ents. Mcasures of maximization criterion of or minimaximin can be used to intuitively or experientially define the de criteria [19]. Adding risk parameter $\lambda r$ to MGSC equation creates a new risk-modified Gaussian S-curve (RMGSC) (4) (Fig. 7) suitable for simulating and generating as accurate a

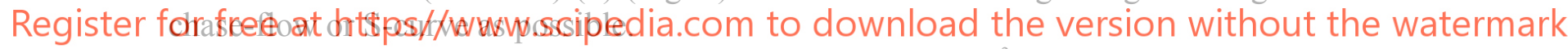
$\operatorname{skvGr}(x, T)=\lambda r \cdot \lambda k v \cdot \int_{0}^{x} \frac{1}{(a \cdot T+b) \cdot \sqrt{2 \cdot \pi}} \cdot e^{\frac{-(x-\mu)^{2}}{k v \cdot(a \cdot T+b)}} d x$

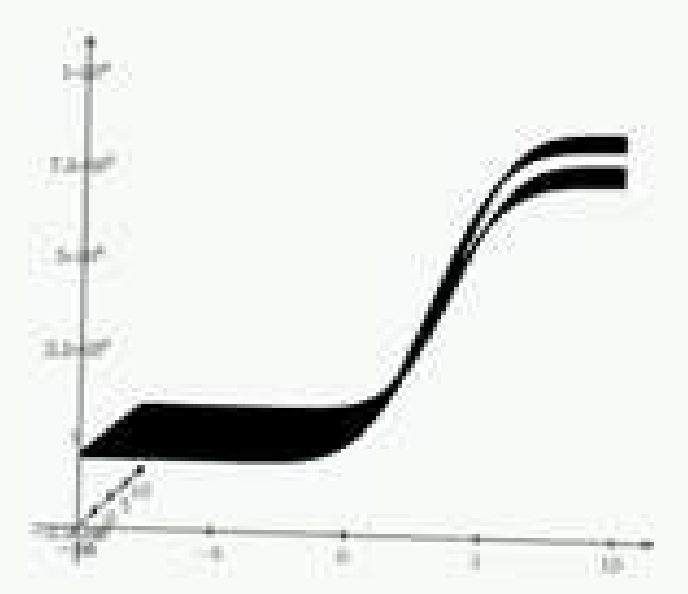

Figure 7: MGSC and RMGSC 
Risk coefficient $\lambda r$ was developed from the relation between planned and finalized MGSC equation. This coefficient increases the S-curve value and we can easily estimate project risk in regard to the plan. Thus, RMGSC number rendering creates a project development simulation while including all possible risk scenarios (Fig. 8).
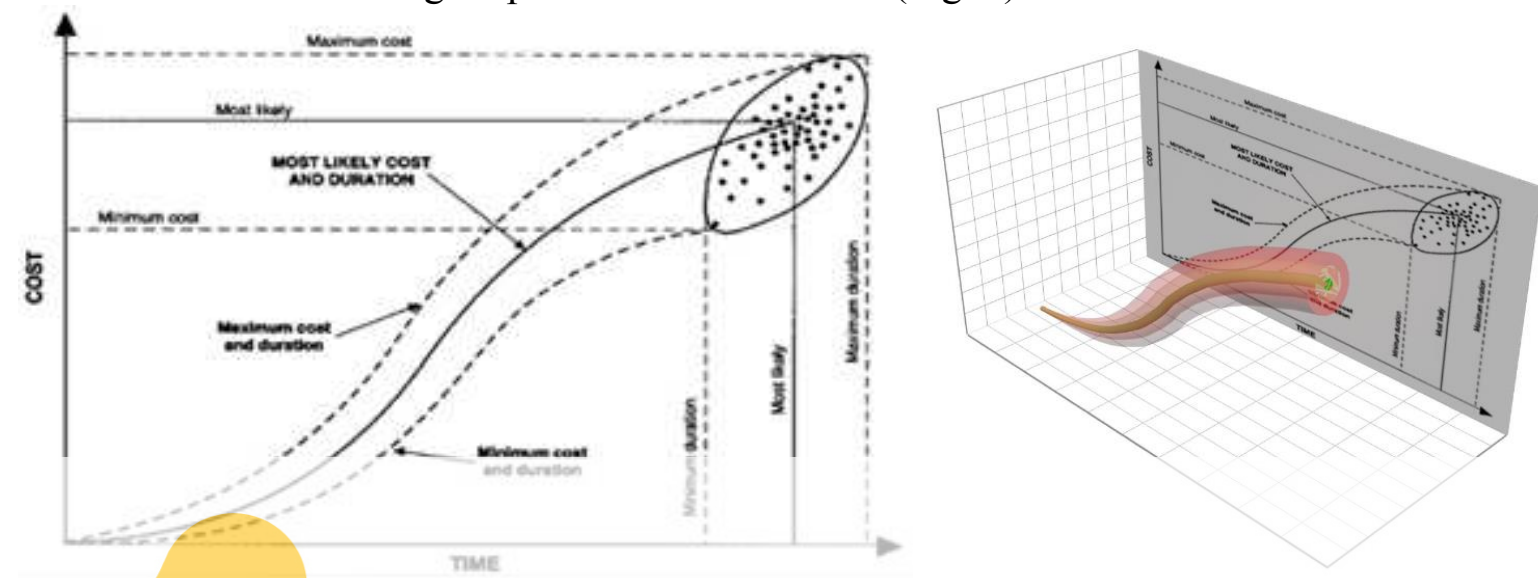

Figure 8: Project simulation using risk dispersion and variables $t$ and T (Barraza, Back \& Mata \& author)

Finally, simulations based on natural processes according to the Gaussian distribution are normal, but it was observed that the MGSC curve in all directions can simultaneously display a natural wave (Fig. 9) which should be used for new FEM mesh and computer graphics technologies based on natural events
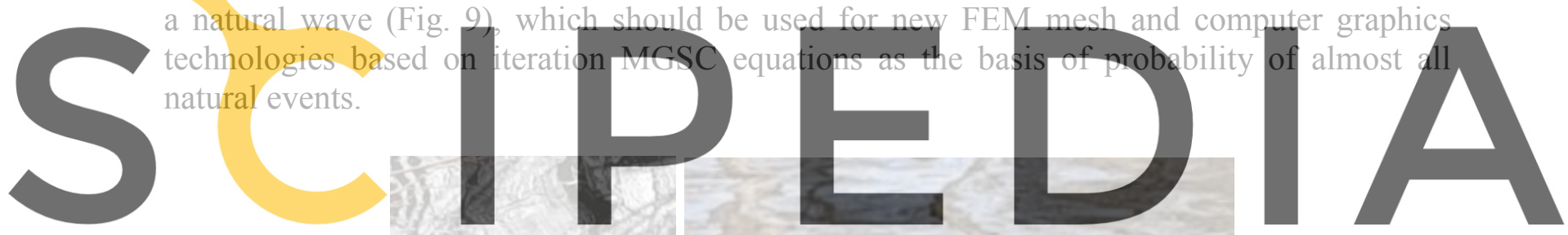

Register for free at https//www.scipedia.com to download the version without the watermark
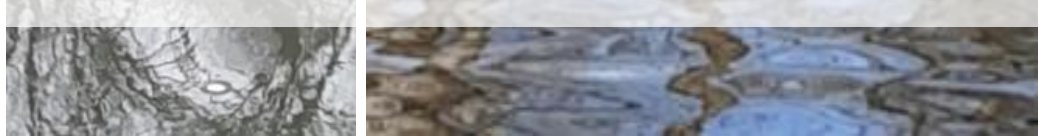

Figure 9. Radial natural wave - in the direction of the $\mathrm{x}$ and $\mathrm{y}$ axes of the shadows trees on the Mura River

\section{CONCLUSION}

Iterative mathematical models are key algorithms (codes) for new CAD, DT and CPS systems. Existing software algorithms for defining curves shift the point of direction y' or a sequence at a certain interval with a given weight sequence. A series of monitored intervals is required to define the S-curve while MGSC resolves this in a single given interval, although not completely automatically. It is necessary to gather more statistical field data and update the proposed linear model with more realistic coefficients.

MGSC is becoming a flexible tool for defining project future in terms of duration and time. Therefore, vector representation of the S-curve as a function of two main project variables creates a modern $3 \mathrm{D}$ model of project execution, or more precisely, investment 
monitoring by simulating project regulation. Measuring or quantifying risk by means of standard deviation or standard deviation of $\sigma \mathrm{MGSC}$ events creates project risk probability or RMGSC equation. For the hypothesis to be accurate, it is necessary to have an appropriate database allowing determination of the probability magnitude, i.e. risk coefficient $\lambda r$ and consequently a direct calculation of risk impact on duration, cost and quality. What is expected is further automation in defining time and cost component shifts in the S-curve regarding the functional complement of the risk variable.

The combinatorial equation [20] includes all planned activities and event vectors by homogeneous Markov processes in millions of combinations, optimizing the critical path in production process at a certain S-curve interval.

For the risk coefficient $\lambda r$ to be as realistic as possible, it is necessary to explore the database of finalized and planned projects in more detail. In the next step, it is recommended to educate a creative team manager of corporate security who also has competencies and skills of an IT manager [21] and use a new simulation tool for business project perspectives. A viable business model using artificial intelligence (AR) [22] and CPS can bring FEM mesh technological and organizational breakthroughs in project management standards.

\section{REFERENCES}

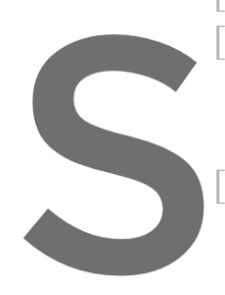

[1] Orešković, M.

[2] Križaić, V. and dinamičkog strukturnog (2019) 1:117-126.

Huang, C. and Fisher, N Planning (ERP) Company. International J
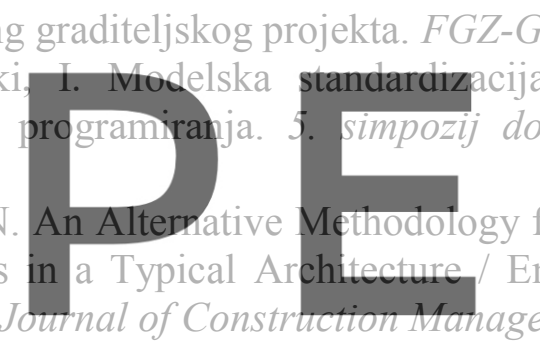

[4] Oti, A. and Tizani, W. and Abanda, F.H. and Yaly-Zada, A. and Tah, J.

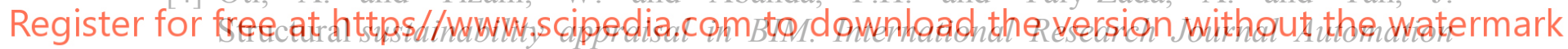
in Construction (2016) 5:44-58.

[5] Zangh, S. and Zangh, L. and Wang, D. and Zhou, B. and Le, Z. Research on the Stability of Urban Bus Network Based on Complex Networks Theory, Hilbert Space. ASCE (2019) https://doi.org/10.1061/9780784482292.154.

[6] Guler, H. Optimizacija održavanja i remonta željezničkih kolosijeka primjenom genetičkih algoritama. FGZ - Građevinar (2016) 12: 979-993.

[7] Fallera, C. and Höftmanna. Service-oriented communication model for cyber-physicalproduction-systems. Conference on Intelligent Computation in Manufacturing Engineering (2018) 1:156 - 161.

[8] Lee, K. Principles of CAD/CAM/CAE systems. Addision-Wesley, (1999).

[9] Cahyono, M.A. Suwandi, R. Pemodelan matematik system hidrolik pada main landing gear extension dan retraction pesawat Boeing 737-900ER dengan program MatlabSimulink. Angkasa Template, (2017).

[10] Križaić, V. Organization limit - Modeling and simulation. International Conference SCCM (1994) 1:335-349.

[11] Vranjković, P. Booleova algebra. Element, (1998). 
[12] DashWu, D. and Kefan, X. and Gang, C. and Ping, G. A Risk Analysis Model in Concurrent Engineering Product Development. Risk Analysis (2010) 9:1440-53.

[13] Vukadinović, S. Masovno opsluživanje. Naučna knjiga, (1988).

[14] Ai, J. and Brockett, P. and Wang, T. Optimal Enterprise Risk Management and Decision Making With Shared and Dependent Risks. Journal of Risk \& Insurance (2017) 4:1127-1169.

[15] Barraza, G.A. and Back, W.E. and Mata, F. Probabilistic Forecasting of Project Performance Using Stochastic S Curves. Journal of construction Engineering and Managament (2004) downloaded from ascelibrary.org by University Of Zagreb Faculty Of Civil Engineering 1:25-32.

[16] Pauše, Ž. Vjerojatnost, informacija, stohastički procesi. Školska knjiga, (1988).

[17] Vukadinović, S. Elementi teorije verovatnoće $i$ matematičke statistike. NIGRO, (1988).

[18] Križaić, V. and Hranj, D. Project Management by Modified Gaussian S-curve. OTMC (2019) 1:208.

[19] Newbold, P. and Carlson, W. and Thorne, B. Statistika za poslovanje i ekonomiju. MATE, (2010).

[20] Križaić, V. Planning through combinatorics. VII International conference Organization, technology and management in construction (2006).

[21] Šarčević, M. Komunikacijska uloga i kompetencije IT menadžera. Filozofski fakultet, (2016).
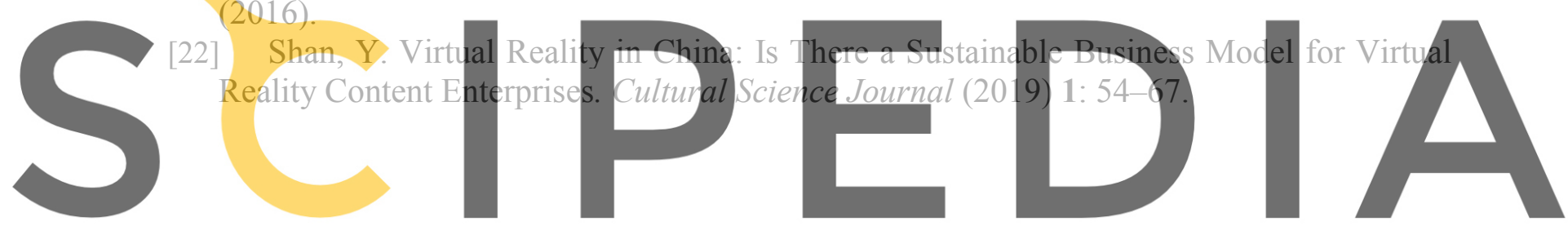

Register for free at https//www.scipedia.com to download the version without the watermark 